\title{
Neutron Generation Time in Highly- Enriched Uranium Core at Kyoto University Critical Assembly
}

\author{
AUTHOR(S): \\ Pyeon, Cheol Ho; Yamanaka, Masao; Endo, \\ Tomohiro; Chiba, Go; Van Rooijen, Willem F. G; \\ Watanabe, Kenichi
}

\section{CITATION:}

Pyeon, Cheol Ho ... [et al]. Neutron Generation Time in Highly-Enriched Uranium Core at Kyoto University Critical Assembly. Nuclear Science and Engineering 2020, 194(12): 11161127

\section{ISSUE DATE:}

2020

URL:

http://hdl.handle.net/2433/259297

\section{RIGHT:}

This is an Accepted Manuscript of an article published by Taylor \& Francis in Nuclear Science and Engineering on $7 \mathrm{July}$ 2020, available online: http://www.tandfonline.com/10.1080/00295639.2020.1774230.; The full-text file will be made open to the public on 7 July 2021 in accordance with publisher's 'Terms and Conditions for Self-Archiving.; この論文は 出版社版でありません。引用の際には出版社版をご確認ご利用ください。; This is not the published version. Please cite only the published version. 


\section{Neutron Generation Time in Highly-Enriched Uranium Core at Kyoto University Critical Assembly}

Cheol Ho Pyeon*a, Masao Yamanaka*a ${ }^{* *}$ Tomohiro Endo ${ }^{\mathrm{b}}, \mathrm{Go}_{\mathrm{Chiba}}^{\mathrm{c}}$, Willem F. G. van Rooijen ${ }^{d}$ and Kenichi Watanabe ${ }^{b}$

a Institute for Integrated Radiation and Nuclear Science, Kyoto University,

Asashiro-nishi, Kumatori-cho, Sennan-gun, Osaka 590-0494, Japan

${ }^{\mathrm{b}}$ Graduate School of Engineering, Nagoya University,

Furo-cho, Chikusa-ku, Nagoya 464-8601, Japan

${ }^{\mathrm{c}}$ Graduate School of Engineering, Hokkaido University,

Nishi 8, Kita 13, Kita-ku, Sapporo 060-8628, Japan

${ }^{\mathrm{d}}$ Research Institute of Nuclear Engineering, University of Fukui,

Kanawa-cho, Tsuruga-shi, Fukui 914-0055, Japan

*Corresponding author. Email: pyeon@rri.kyoto-u.ac.jp

** Present address: Nuclear Engineering, Ltd, 1-3-7, Tosabori, Nishi-ku, Osaka 550-0001, Japan 


\begin{abstract}
At the Kyoto University Critical Assembly, experiments on kinetics parameters are carried out at near-critical configurations, super-critical and subcritical states, in the thermal neutron spectrum made with a highly-enriched uranium fuel. The main calculated kinetics parameters, the effective delayed neutron fraction $\left(\beta_{e f f}\right)$ and the neutron generation time $(\Lambda)$ are used effectively for the estimation of experimental parameters, and the accuracy of experiments on prompt neutron decay constant $(\alpha)$ and subcriticality $(\rho)$ in dollar units is attained by the numerical results of $\beta_{\text {eff }}$ and $\Lambda$. Furthermore, the value of $\beta_{\text {eff }} / \Lambda$ is experimentally deduced with the use of the experimental results of $\alpha$ and $\rho$, ranging between 250 and $-80 \mathrm{pcm}$. Thus, the experimentally deduced values of $\beta_{\text {eff }} / \Lambda$ that reveal good accuracy through a comparison with those by the MCNP6.1 calculations with JENDL-4.0 are then taken as an index of $\Lambda$ by introducing an acceptable assumption of $\beta_{\text {eff }}$ at near-critical configurations. From the results of experimental and numerical analyses, the experimental value of $\beta_{\text {eff }} / \Lambda$ is important for the validation of $\Lambda$, since kinetics parameters are successfully obtained from the clean cores of near-critical configurations in the thermal neutron spectrum.
\end{abstract}

KEYWORDS: Neutron generation time, Highly-enriched uranium core, KUCA, Near critical, Thermal neutron spectrum 


\section{INTRODUCTION}

Kinetics parameters in nuclear reactor physics that include the effective delayed neutron fraction $\left(\beta_{e f f}\right)$ and neutron generation time $(\Lambda)$ are important in ascertaining safe operation of nuclear reactor cores. At the critical state in a reactor core, excess reactivity and control rod worth are experimentally attained by the positive period method [1] and the rod drop method [2], respectively, after obtaining the values of $\beta_{\text {eff }}$ and neutron life time $(\ell)$ by numerical calculations. Also, at the subcritical state, prompt neutron decay constant $(\alpha)$ and subcriticality in dollar units $(\rho \$)$ are measurable by the pulsed-neutron source (PNS) method [3] and the noise methods (the Feynman- $\alpha$ method [4] and the Rossi- $\alpha$ method [5]). Among these reactor physics parameters, however, both $\beta_{\text {eff }}$ [6] and $\Lambda$ are considered difficult to obtain directly by reactor physics experiments at super-critical, critical and subcritical states.

In the accelerator-driven system (ADS) experiments at the Kyoto University Critical Assembly (KUCA), real-time measurements [7]-[8] of $\alpha$ and $\rho \$$ were made in attempts to satisfy sufficient reliability of the measured accuracy of experimental results. Also, at KUCA, experimental analyses of $\beta_{\text {eff }}$ were conducted by Monte Carlo calculations with the use of ADS experimental results, demonstrating the dependence of external neutron source [9] and the measurement methodology [10] with respect to $\beta_{\text {eff. }}$ Moreover, a variation in the ratio of $\beta_{\text {eff }}$ and $\Lambda\left(\beta_{\text {eff }} / \Lambda\right)$ obtained by the $\alpha$-fitting method [11] was experimentally examined on subcriticality in hard neutron spectrum cores [12]-[14], with the combined use of the experimental results of $\alpha$ and $\rho$ s. Numerical analyses of $\beta_{\text {eff }}$ and $\Lambda$ were conducted with Monte Carlo calculations together with the use of experimental data obtained at other ADS facilities [15]-[16].

Among many benchmark problems of kinetics parameters, the GODIVA I experiments [17]-[20] are very useful in determining the numerical precision of kinetics parameters, particularly those including $\beta_{\text {eff }}$ and $\Lambda$, by stochastic and deterministic approaches. In the experimental database [20], kinetics parameters obtained by the GODIVA I experiments are 
interestingly prepared, particularly, for a very simple core configuration that is available to model easily by numerical calculations, and used for validation of the transport calculation codes. The main characteristics of the GODIVA I experiments are a sphere system with one region and a fast neutron spectrum core with highly-enriched uranium (HEU), for providing experimental results of near-critical configurations ranging between about 450 (excess reactivity) and -150 (subcriticality) pcm. Also, kinetics parameters $\beta_{\text {eff }}=680 \mathrm{pcm}$ and $\Lambda=6.2 \mathrm{~ns}$ are different from those in a thermal spectrum core. Meanwhile, in ADS experiments at KUCA, kinetics parameters of $\alpha$ and $\rho$ were successfully obtained with the combined use of the KUCA core and external neutron sources (14 MeV neutrons and $100 \mathrm{MeV}$ protons). Here, the KUCA core was composed of the HEU fuel and a polyethylene moderator (Table I), with a thermal neutron spectrum. Interestingly, using parameters $\alpha$ and $\rho$ in the KUCA core, the values of $\beta_{\text {eff }} / \Lambda$ were deduced at near-critical configurations ranging between 250 and $-80 \mathrm{pcm}$ through experimental analyses, and compared well with Monte Carlo calculations.

To estimate the numerical precision of $\Lambda$, the value of $\beta_{\text {eff }} / \Lambda$ was used as an index of $\Lambda$ evaluation that is defined by a ratio of $\Lambda$ values in super-critical and subcritical states. The main objectives of this study were to examine the validity of evaluating $\Lambda$ with the use of the value of $\beta_{\text {eff }} / \Lambda$, and providing a relative value obtained by the two results of super-critical and subcritical states. The details of experimental settings are presented in Sec. II, and the results of the comparison between experiments and calculations are discussed in Sec. III. Finally, the conclusions are summarized in Sec. IV.

\section{EXPERIMENTAL SETTINGS}

\section{II.A. Core Configurations}

Among three cores (termed A, B and C) at KUCA, A and B are polyethylene 
solid-moderated and solid-reflected cores, and $\mathrm{C}$ is a light water-moderated and water-reflected one. The three cores are operated at zero power in the normal operating state. Critical cores set in the A-core (Figs. 1 and 2) have polyethylene moderator and reflector rods, and three different fuel assemblies: normal "F" (Fig. 3), partial "8" and "4" (Figs. 4 and 5) corresponding to Figs. 1 and 2, respectively. The normal fuel assembly "F" is composed of 60 unit cells, and upper and lower polyethylene blocks about 23" and 21" long, respectively, in an aluminum (Al) sheath $(2.1 \times 2.1 \times 60$ ") . A unit cell is composed of two HEU fuel plates $2 \times 2$ " square and $1 / 8$ " thick $(1 / 16 " \times 2)$, polyethylene $(p)$ plate $2 \times 2$ " square and $1 / 8$ " thick, for normal fuel plate "F." Numeral "8" represents a partial fuel assembly composed of 8 unit cells, with two HEU fuel plates and a polyethylene plate as in the normal fuel assembly, providing 52 unit cells of two Al plates $2 \times 2$ " square and $1 / 8$ " thick $(1 / 16 " \times 2)$, and $1 / 8$ " polyethylene plates. Also, numeral "4" corresponds to 4 unit cells of fuel assembly with 56 unit cells composed of Al and polyethylene plates.

\section{II.B. Experiments}

In the two critical cores shown in Figs. 1 and 2, criticality was reached at positions of control (C1, C2 and C3) and safety (S4, S5 and S6) rods for the total number of HEU fuel plates: 3016 and 3008, as shown in Tables II and III, respectively. Excess reactivity and control rod worth in pcm units were then experimentally obtained by the positive period method and the rod drop method, respectively, with the use of two kinetics parameters $\beta_{\text {eff }}$ and $\ell$ estimated by numerical calculations. Here, excess reactivity obtained experimentally was about 250 and 100 pcm in Figs. 1 and 2, respectively, and control rod worth of C1, C2 (Fig. 1 or C3 in Fig. 2) and C3 (Fig. 2 or C2 in Fig. 1) was about 880, 150 and 520 pcm, respectively.

In the ADS core (3000 HEU fuel plates) at the subcritical state, deuteron beams were injected onto a tritium target set at $(14-15, \mathrm{X})$ in Fig. 6. In the same subcritical core, another external neutron source of $100 \mathrm{MeV}$ proton beams was injected onto a lead-bismuth $(\mathrm{Pb}-\mathrm{Bi})$ 
target set at $(15, \mathrm{H})$ in Fig. 7. Two different external neutron sources (14 MeV neutrons; 100 $\mathrm{MeV}$ protons: spallation neutrons) were separately injected into the subcritical core: deuteron beams, $0.1 \mathrm{~mA}$ current, $20 \mathrm{~Hz}$ repetition rate, $97 \mu \mathrm{s}$ width and $1 \times 10^{5} \mathrm{~s}^{-1}$ neutron yield; $100 \mathrm{MeV}$ protons, $0.1 \mathrm{nA}$ current, $20 \mathrm{~Hz}$ repetition rate, $100 \mathrm{~ns}$ width and $1 \times 10^{7} \mathrm{~s}^{-1}$ neutron yield. The $\mathrm{Pb}$-Bi target was $50 \mathrm{~mm}$ in diameter and $18 \mathrm{~mm}$ thick. In a series of ADS experiments and during the injection of external neutron source, $\alpha$ and $\rho$ s were measured by the least-square fitting method and the extended area ratio method [21], respectively.

Moreover, to examine the effects of detector position dependence [22] and external neutron source spectrum on measurement results, three optical fiber detectors [23] were set at (14-15, L-M); (13-14, K-L); (12-13, J-K) in Fig. 6 and (15-16, O-Q); (16-17, Q-R); (18-19, S-T) in Fig. 7; also, three BF-3 detectors were at $(15, \mathrm{H}) ;(11, \mathrm{I}) ;(11, \mathrm{M})$ in Fig. 6 and $(15, \mathrm{U}) ;(11, \mathrm{~T}) ;(10$, O) in Fig. 7.

\section{II.C. Kinetics Parameters}

For the $\alpha$-fitting method [11], $\alpha$ is easily deduced by combining subcriticality $\left(-\rho_{\mathrm{pcm}}\right)$ in pcm units, $\beta_{\text {eff }}$ and $\Lambda$ as follows:

$$
\alpha=\frac{\beta_{e f f}-\rho_{\mathrm{pcm}}}{\Lambda}
$$

The relationship between $\rho_{\mathrm{pcm}}$ and $\rho$ is expressed with the use of $\beta_{\text {eff }}$ as follows:

$$
\rho_{\mathrm{pcm}}=\rho_{\$} \beta_{e f f}
$$

Substituting Eq. (2) for Eq. (1), $\beta_{\text {eff }} / \Lambda$ can be expressed as follows: 


$$
\frac{\beta_{e f f}}{\Lambda}=\frac{\alpha}{1-\rho_{\mathrm{S}}} .
$$

The value of $\beta_{e f f} / \Lambda$ is easily deduced from the experimental results of $\alpha$ and $\rho$ s.

\section{RESULTS AND DISCUSSION}

\section{III.A. Eigenvalue Calculations}

For transport, numerical calculations were performed by the Monte Carlo transport code, MCNP6.1 [24] together with nuclear data libraries, JENDL-4.0 [25] and ENDF/B-VII.1 [26]. Here, in MCNP6.1, since the effects of reactivity by neutron detectors (optical fiber detectors, BF-3 detectors, fission chambers and uncompensated ionization chambers) and control (safety) rods are not negligible, neutron detectors and control (safety) rods were modeled precisely in the simulated geometry and transport calculations. The precision of numerical criticality in pcm units was attained by the eigenvalue calculations with a total of $5 \times 10^{8}$ histories $\left(1 \times 10^{5}\right.$ histories per cycle, $5 \times 10^{3}$ active cycles and $1 \times 10^{2}$ skip cycles) and a statistical error of about $4 \mathrm{pcm}$. Also, main kinetics parameters, $\beta_{\text {eff }}, \Lambda$ and Rossi- $\alpha$ (termed $\beta_{\text {eff }} / \Lambda$ in MCNP6.1) values, were obtained by the eigenvalue calculations, when obtaining the effective multiplication factor by the k-code option.

To confirm the numerical precision of eigenvalue calculations by MCNP6.1, excess reactivity and control rod worth $(\mathrm{C} 1, \mathrm{C} 2$ and $\mathrm{C} 3)$ were compared with those obtained from the experiments by the positive period method and the rod drop method, respectively. The MCNP eigenvalue calculations in critical state are not always unit, differing from the experimental results in in critical state obtained by nuclear data accuracy and uniformed number density 
approximation in core materials, although a critical core configuration is more closely simulated by MCNP. Thus, excess reactivity $\rho_{\text {excess }}^{\text {cal }}$ in pcm units was numerically deduced by the difference between two effective multiplication factors $k_{\text {critical }}$ and $k_{\text {super-critical, }}$ in critical and super-critical (clean) cores, respectively, as follows:

$$
\rho_{\text {excess }}^{\text {cal }}=\frac{1}{k_{\text {critical }}}-\frac{1}{k_{\text {super-critical }}}
$$

Also, control rod worth was numerically deduced by the difference between the critical and the subcritical (rod insertion) cores, as in Eq. (4).

Using the kinetics parameters obtained by MCNP6.1, experimental reactivity $\rho^{\text {exp }}$ was deduced and compared with numerical reactivity $\rho^{\text {cal }}$ obtained by JENDL-4.0 and ENDF/B-VII.1, as shown in Tables IV through VII, with the consideration of statistical errors of neutron counts obtained from the neutron detectors and processing of error propagation caused by experimental analyses. For the critical cores (3016 and 3008 HEU plates in Tables II and III) shown in Figs. 1 and 2, respectively, numerical reactivity obtained by JENDL-4.0 revealed a fairly good agreement with the experimental reactivity within a relative difference around $5 \%$ through the $\mathrm{C} / \mathrm{E}$ (calculation/experiment) value of excess reactivity and control rod worth, as shown in Tables IV and VI. In terms of ENDF/B-VII.1, the difference between numerical and experimental reactivity was relatively large over $10 \%$, as shown in Tables V and VII. The difference between

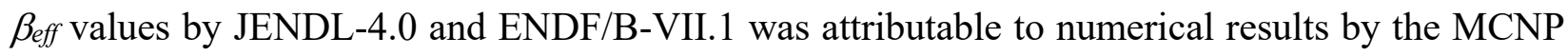
calculations in fraction $\beta_{i}\left(i=1\right.$ to 6 : precursor group of delayed neutrons) and decay constant $\lambda_{i}$ of delayed neutrons, as shown in Figs. 8 and 9, respectively.

As shown in Tables IV through VII, numerical results (eigenvalue calculations) by MCNP6.1 with JENDL-4.0 demonstrated good agreement with the experimental data of 
reactivity in the critical cores. JENDL-4.0 was taken as a reference library by comparing it with ENDF/B-VII.1.

\section{III.B. Experimental Analyses of $\beta_{\text {eff }} / \Lambda$}

Kinetics parameters $\beta_{\text {eff, }} \Lambda$ and Rossi- $\alpha$, and $k_{\text {eff }}$ values were obtained by the MCNP eigenvalue calculations and compared with those of JENDL-4.0 and ENDF/B-VII.1, for critical and near-critical states, as shown in Tables VIII, IX and X. For the two critical cores shown in Figs. 1 and 2, JENDL-4.0 demonstrated a small difference between the super-critical (Table VIII) and the critical (Table IX) states, because of the slight difference in the number of fuel plates: 3016 and 3008. Also, in terms of ENDF/B-VII.1, the three kinetics parameters were almost the same in the two states.

At the subcritical state with 3000 fuel plates, three kinetics parameters showed a meaningful change from the critical state, although the subcriticality was very small and around the criticality (Table X). Kinetic parameters $\alpha$ and $\rho$ s were then obtained by the extended area ratio method and the least-square fitting method, respectively, by varying the external neutron source: $14 \mathrm{MeV}$ neutrons (Table XI) and spallation neutrons (Table XII). Also, as shown in Tables XI and XII, detector position dependency revealed interestingly: the results of Fiber \#1 and BF-3 \#3 were rather good, and on the contrary, those of Fiber \#2, BF-3 \#1 and BF-3 \#3 looked problematic.

On the basis of the experimental results of $\alpha$ and $\rho$, the value of $\left(\beta_{\text {eff }} / \Lambda\right)^{\exp }$ was experimentally deduced by Eq. (3) for $14 \mathrm{MeV}$ neutrons (Table XI) and spallation neutrons (Table XII), and compared with that of $\left(\beta_{\text {eff }} / \Lambda\right)_{\mathrm{J} 40}^{\mathrm{cal}}$ obtained by MCNP6.1 together with JENDL-4.0. With the $14 \mathrm{MeV}$ neutrons, since subcriticality in pcm units was found to be near-critical, about $16.7 \pm 4.5 \mathrm{pcm}$, the value of $\left(\beta_{\text {eff }} / \Lambda\right)_{\mathrm{J} 40}^{\mathrm{cal}}$ was observed the same as that of $\alpha$. 
The result was considered valid at a shallow subcritical state. Among optical fibers and BF-3 detectors, Fiber \#1 revealed a fairly good agreement with the MCNP calculation within a relative difference of $4 \%$ in the $\mathrm{C} / \mathrm{E}$ value (Table $\mathrm{XI}$ ), which was attributable to the location of Fiber \#1 near the center of the core (Fig. 1): the position dependence caused by the spatial effect was very small on the experimental results of $\alpha$ and $\rho$. Also, with the spallation neutrons (Table XII), Fiber \#1 demonstrated the same accuracy about $2 \%$ in the $\mathrm{C} / \mathrm{E}$ value as with $14 \mathrm{MeV}$ neutrons, although the subcriticality in pcm units was about $78.4 \pm 2.2 \mathrm{pcm}$. The value of $\left(\beta_{\text {eff }} / \Lambda\right)^{\exp }$ was found to be experimentally valid in the deduction of kinetics parameters, through a comparison between the experiments and the MCNP6.1 calculations with JENDL-4.0 (Tables XI and XII).

\section{III.C. Discussion}

Experimental analyses of the ADS with spallation neutrons at KUCA have clearly demonstrated that the value of $\beta_{\text {eff }}$ has a little effect on the evaluation of subcriticality in pcm units converted from that in dollar units, when compared with the results of numerical subcriticality in pcm units [4]. In the present study, considering that the values of $\beta_{\text {eff }}$ are almost the same in the near-critical configurations, particular attention was directed to kinetic parameter $\Lambda$ obtained by combining $\alpha$ and $\rho$.

The values of $\beta_{\text {eff }}$ by MCNP6.1 with JENDL-4.0 in the super-critical (3008 HEU fuel plates) and subcritical (3000 plates) configurations, were $812 \pm 10$ and $806 \pm 10 \mathrm{pcm}$, as shown in Tables IX and $\mathrm{X}$, respectively. Since the values of $\beta_{\text {eff }}$ are almost the same and within the allowance of experimental uncertainty, the ratio of $\left(\beta_{\text {eff }} / \Lambda\right)_{\text {super-critical }}^{\text {cal }}$ and $\left(\beta_{\text {eff }} / \Lambda\right)_{\text {subcritical }}^{\text {cal }}$ in the near-critical configurations is approximated as follows:

$$
\left(\beta_{\text {eff }} / \Lambda\right)_{\text {super-critical }}^{\text {cal }} /\left(\beta_{\text {eff }} / \Lambda\right)_{\text {subcritical }}^{\text {cal }} \approx\left(\Lambda_{\text {subcritical }} / \Lambda_{\text {super-critical }}\right)^{\text {cal }}
$$


Here, Eq. (5) is defined as "Lambda ratio" that is a relative value of $\Lambda$ in the near-critical configurations. From the results of Tables XI and XII, assuming that the value of $\left(\beta_{\text {eff }} / \Lambda\right)_{\text {subcritical }}^{\text {cal }}$ in the subcritical state by MCNP6.1 is equal to that of $\left(\beta_{\text {eff }} / \Lambda\right)^{\text {exp }}$ by the experiment, Eq. (5) can finally be written as follows, by substituting $\left(\beta_{\text {eff }} / \Lambda\right)_{\text {subcritical }}^{\text {cal }}$ for $\left(\beta_{\text {eff }} / \Lambda\right)^{\text {exp }}$ and applying again the assumption with respect to $\beta_{\text {eff }}$ in Eq. (5):

$$
\left(\beta_{\text {eff }} / \Lambda\right)_{\text {super-critical }}^{\text {cal }} /\left(\beta_{\text {eff }} / \Lambda\right)^{\text {exp }} \approx \Lambda^{\text {exp }} / \Lambda_{\text {super-critical }}^{\text {cal }} .
$$

On the basis of the validity of $\left(\beta_{\text {eff }} / \Lambda\right)^{\text {exp }}$ mentioned in Sec. III.B., Eq. (6) can be interpreted as a kind of Lambda ratio between the experiments and the calculations, with the combined use of $\left(\beta_{\text {eff }} / \Lambda\right)_{\text {super-critical }}^{\text {cal }}$ and $\left(\beta_{\text {eff }} / \Lambda\right)^{\text {exp }}$. Actually, the value of $\left(\beta_{\text {eff }} / \Lambda\right)^{\exp }$ obtained by the ADS experiments at KUCA can be used as an index of $\Lambda$ in the near-critical configurations, and is, indeed, expected to be applied for the validation of $\Lambda$, by stochastic and deterministic calculations, at near-critical configurations in a thermal neutron spectrum core.

\section{CONCLUSIONS}

Main kinetics parameters, $\alpha$ and $\rho \$$, were experimentally obtained from the KUCA core, and $\beta_{\text {eff }}$ and $\Lambda$, were numerically validated by MCNP6.1, at the near-critical configurations: super-critical and subcritical states. The numerical result of $\left(\beta_{\text {eff }} / \Lambda\right)^{\text {cal }}$ by MCNP6.1 together with JENDL-4.0 compared well with the experimental result of $\left(\beta_{e f f} / \Lambda\right)^{\text {exp }}$ with fairly good accuracy within a relative difference of $4 \%$, while a discrepancy over $10 \%$ was shown in other results. The experimental value of $\left(\beta_{\text {eff }} / \Lambda\right)^{\text {exp }}$ was then available for use as an index of $\Lambda$ in the near-critical configurations, with an attempt at validation of $\Lambda$ by the numerical calculations. 
From the results of experimental and numerical analyses, the importance of the

experimental value of $\left(\beta_{\text {eff }} / \Lambda\right)^{\exp }$ was emphasized for the verification of $\Lambda$, since the kinetics parameters were successfully obtained from the clean cores of near critical configurations (super-critical and subcritical states) in the thermal spectrum core. Also, a series of experimental data obtained at KUCA, including super-critical, critical and subcritical configurations, was potentially conducive to estimating statics and kinetics parameters obtained by the numerical calculations, for nuclear design calculations, such as for thermal spectrum cores.

\section{ACKNOWLEDGEMENTS}

The authors are grateful to all the technical staff at KUCA for their assistance during the experiments.

\section{REFERENCES}

[1] W. S. HOGAN, “Negative-Reactivity Measurements,” Nucl. Sci. Eng., 84, 518 (1960).

[2] G. R. KEEPIN, T. F. WIMETT and R. K. ZEIGLER, "Delayed Neutrons from Fissionable Isotopes of Uranium, Plutonium and Thorium," Phys. Rev., 107, 1044 (1957).

[3] N. SJÖSTRAND, "Measurement on A Subcritical Reactor using A Pulsed Neutron Source," Arkiv för Fysik, 13, 233 (1956).

[4] R. P. FEYNMAN, et al., "Dispersion of the Neutron Emission in U-235 Fission," J. Nucl. Energy, 3, 64 (1956).

[5] G. D. SPIGGS, "A Measurement of the Effective Delayed Neutron Fraction of the Westinghouse Idaho Nuclear Company Slab Tank Assembly using Rossi-a Techniques,” Nucl. Sci. Eng., 62, 105 (1977). 
[6] R. Y. R. KURAMOTO, A. DOS SANTOS, R. JEREZ, et al., “Absolute Measurement of beff based on Feynman-a Experiments and the Two-Region Model in the IPEN/MB-01 Research Reactor,” Ann. Nucl. Energy, 34, 433 (2007).

[7] H. IWAMOTO, K. NISHIHARA, T. YAGI, et al., "On-line Subcriticality Measurement using A Pulsed Spallation Neutron Source,” J. Nucl. Sci. Technol., 54, 432 (2017).

[8] K. WATANABE, T. ENDO, M. YAMANAKA, et al., "Real-Time Subcriticality Monitoring System based on A Highly Sensitive Optical Fiber Detector in An Accelerator-Driven System at the Kyoto University Critical Assembly," J. Nucl. Sci. Technol., 57, 136 (2020).

[9] M. YAMANAKA, C. H. PYEON and T. MISAWA, "Monte Carlo Approach of Effective Delayed Neutron Fraction by k-Ratio Method with External Neutron Source," Nucl. Sci. Eng., 184, 551 (2016).

[10] M. YAMANAKA, C. H. PYEON, S. H. KIM, et al., "Effective Delayed Neutron Fraction in Accelerator-Driven System Experiments with $100 \mathrm{MeV}$ Protons at Kyoto University Critical Assembly,” J. Nucl. Sci. Technol., 54, 293 (2017).

[11] B. E. SIMMONS and J. S. KING, "A Pulsed Technique for Reactivity Determination," Nucl. Sci. Eng., 3, 595 (1958).

[12] C. H. PYEON, M. YAMANAKA, T. ENDO, et al., "Experimental Benchmarks on Kinetic Parameters in Accelerator-Driven System with $100 \mathrm{MeV}$ Protons at Kyoto University Critical Assembly," Ann. Nucl. Energy, 105, 346 (2017).

[13] C. H. PYEON, T. M. VU, M. YAMANAKA, et al., "Reaction Rate Analyses of Accelerator-Driven System Experiments with $100 \mathrm{MeV}$ Protons at Kyoto University Critical Assembly," J. Nucl. Sci. Technol., 55, 190 (2018).

[14] M. YAMANAKA, C. H. PYEON, T. ENDO, et al., "Experimental Analyses of $\beta_{\text {eff }} / \Lambda$ in Accelerator-Driven System at Kyoto University Critical Assembly," J. Nucl. Sci. Technol., 
57, $205(2020)$.

[15] B. VERBOOMEN, W. HAECK and P. BAETEN, "Monte Carlo Calculation of the Effective Neutron Generation Time,” Ann. Nucl. Energy, 33, 911 (2006).

[16] G. PERRET, P. BLAISE, N. MESSAOUDI, et al., "Validation of Monte-Carlo Methods for Generation Time and Delayed Neutron Fraction Predictions," Ann. Nucl. Energy, 97, 165 (2016).

[17] J. T. MIHALCZO, "Prompt-Neutron Lifetime in Critical Enriched-Uranium Metal Cylinders and Annuli," Nucl. Sci. Eng., 20, 60 (1964).

[18] J. T. MIHALCZO, "Prompt Neutron Decay for Delayed Critical Bare and Natural-Uranium-Reflected Metal Spheres of Plutonium and Highly Enriched Uranium,” Nucl. Technol., 175, 498 (2011).

[19] M. A. MARSHALL, "Reactor Physics Measurements and Benchmark Specifications for Oak Ridge Highly Enriched Uranium Sphere (ORSphere)," Nucl. Sci. Eng., 178, 446 (2014).

[20] OECD/NEA, "International Handbook of Evaluated Reactor Physics Benchmark Experiments (IRPhe Project),” No. 7329 (2017).

[21] T. GOZANI, "A Modified Procedure for the Evaluation of Pulsed Source Experiments in Subcritical Reactors," Nukleonik, 4, 348 (1962).

[22] A. TALAMO, Y. GOHAR, S. SADOVICH, et al., "Correction Factor for the Experimental Prompt Neutron Decay Constant,” Ann. Nucl. Energy, 62, 421 (2013).

[23] K. WATANABE, Y. KAWABATA, A. YAMAZAKI, et al., "Development of An Optical Fiber Type Detector using A Eu:liCaAlF6 Scintillator for Neutron Monitoring in Boron Neutron Capture Therapy," Nucl. Instrum. Methods A, 802, 1 (2015).

[24] J. T. GOORLEY, M. R. JAMES, T. E. BOOTH, et al., "Initial MCNP6 Release Overview MCNP6 Version 1.0," Los Alamos National Laboratory, LA-UR-13-22934 (2013). 
[25] K. SHIBATA, O. IWAMOTO, T. NAKAGAWA, et al., "JENDL-4.0: A New Library for Nuclear Science and Technology," J. Nucl. Sci. Technol., 48, 1 (2011).

[26] M. B. CHADWICK, M. HERMAN, P. OBLOZINSKY, et al., "ENDF/B-VII.1 Nuclear Data for Science and Technology: Cross Sections, Covariances, Fission Product Yields and Decay Data," Nucl. Data Sheets, 112, 2887 (2011). 


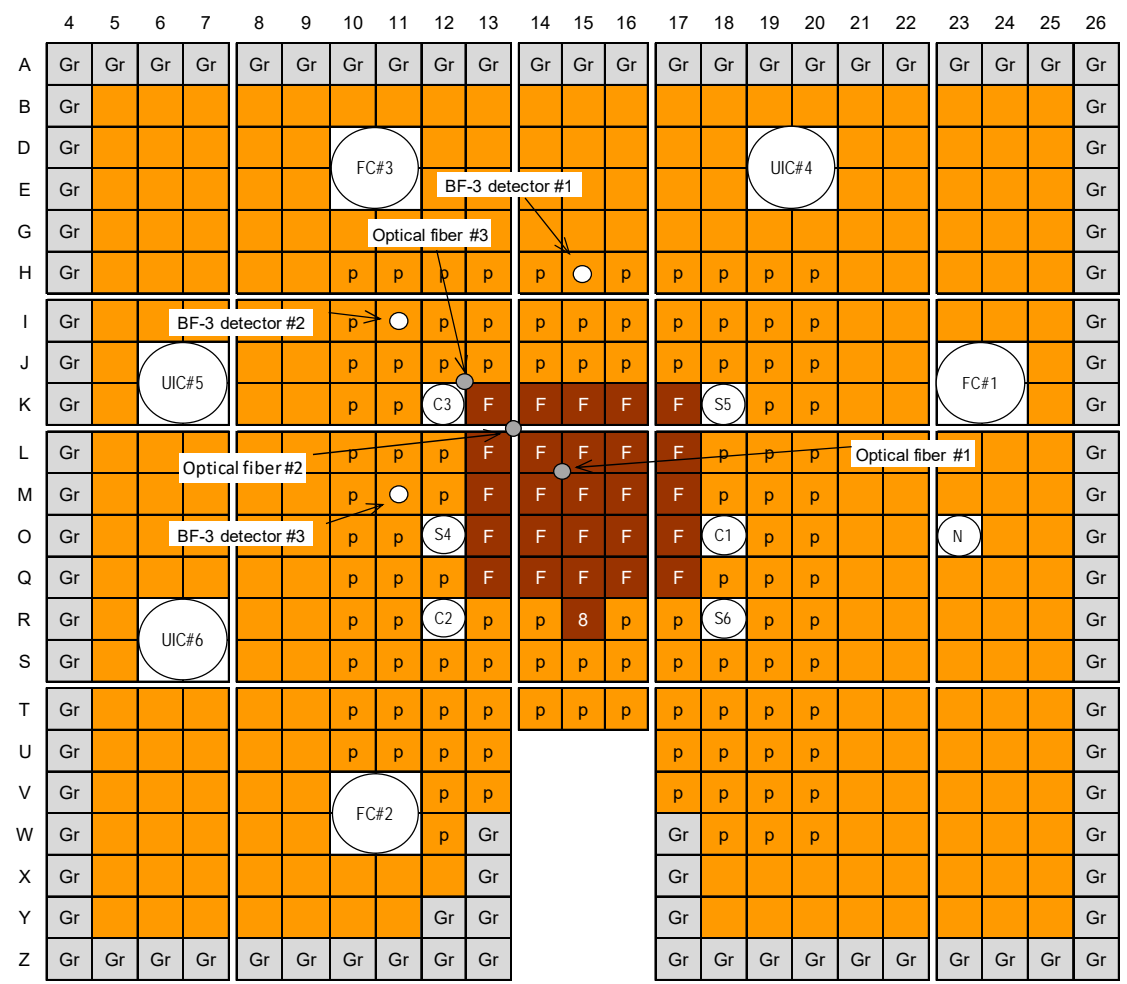

Normal fuel (1/8"p60EUEU)

8 Partial fuel (1/8"p8EUEU)

$\mathrm{p}$ Polyethylene moderator

Polyethylene reflector

Gr Graphite

(C) Control rod

(S) Safety rod

(N) Neutron source (Am-Be)

FC Fission chamber

(UIC) Uncompensated ionization chamber

- $1 / 2$ "diam. BF-3 detector

Optical fiber detector

Fig. 1 Top view of KUCA A-core

(\# of HEU plates: 3016; critical core in Table II) 


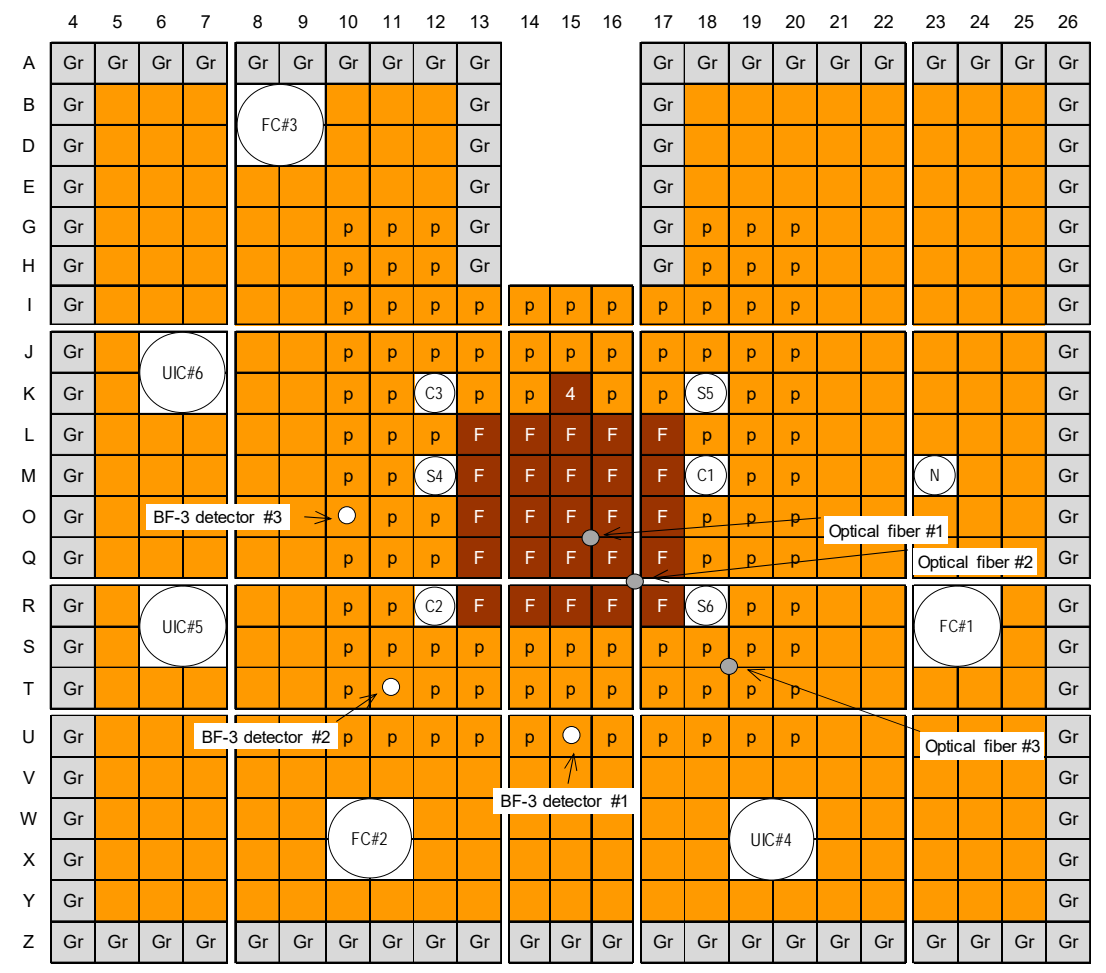

Fig. 2 Top view of KUCA-A core

(\# of HEU plates: 3008; critical core in Table III) 


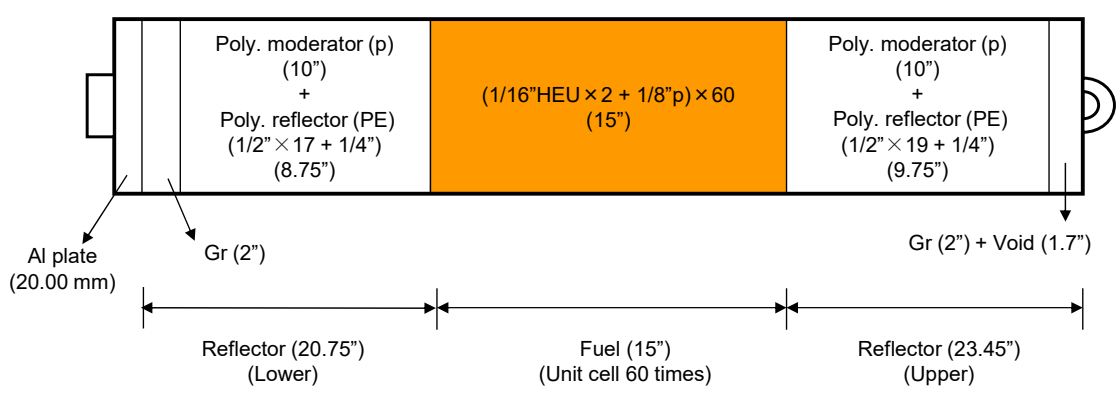

Fig. 3 Schematic drawing of "F" normal fuel rod (1/8"p60EUEU) in Fig. 1

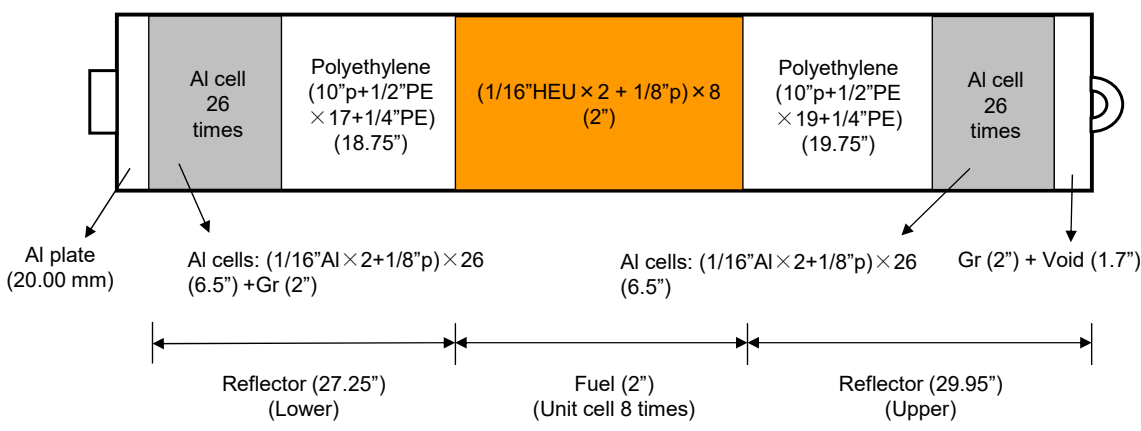

Fig. 4 Schematic drawing of "8" partial fuel rod (1/8"p8EUEU) in Fig. 1

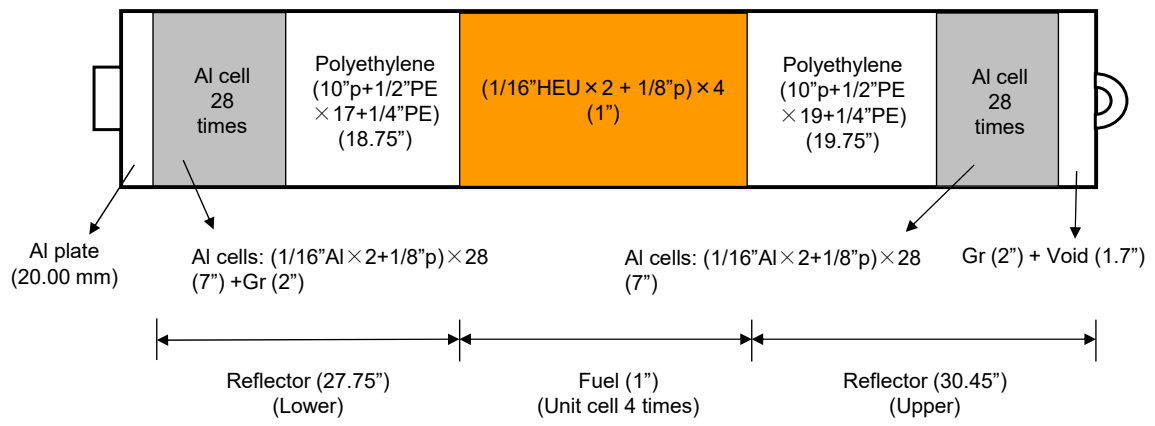

Fig. 5 Schematic drawing of "4" partial fuel rod (1/8"p4EUEU) in Fig. 2 


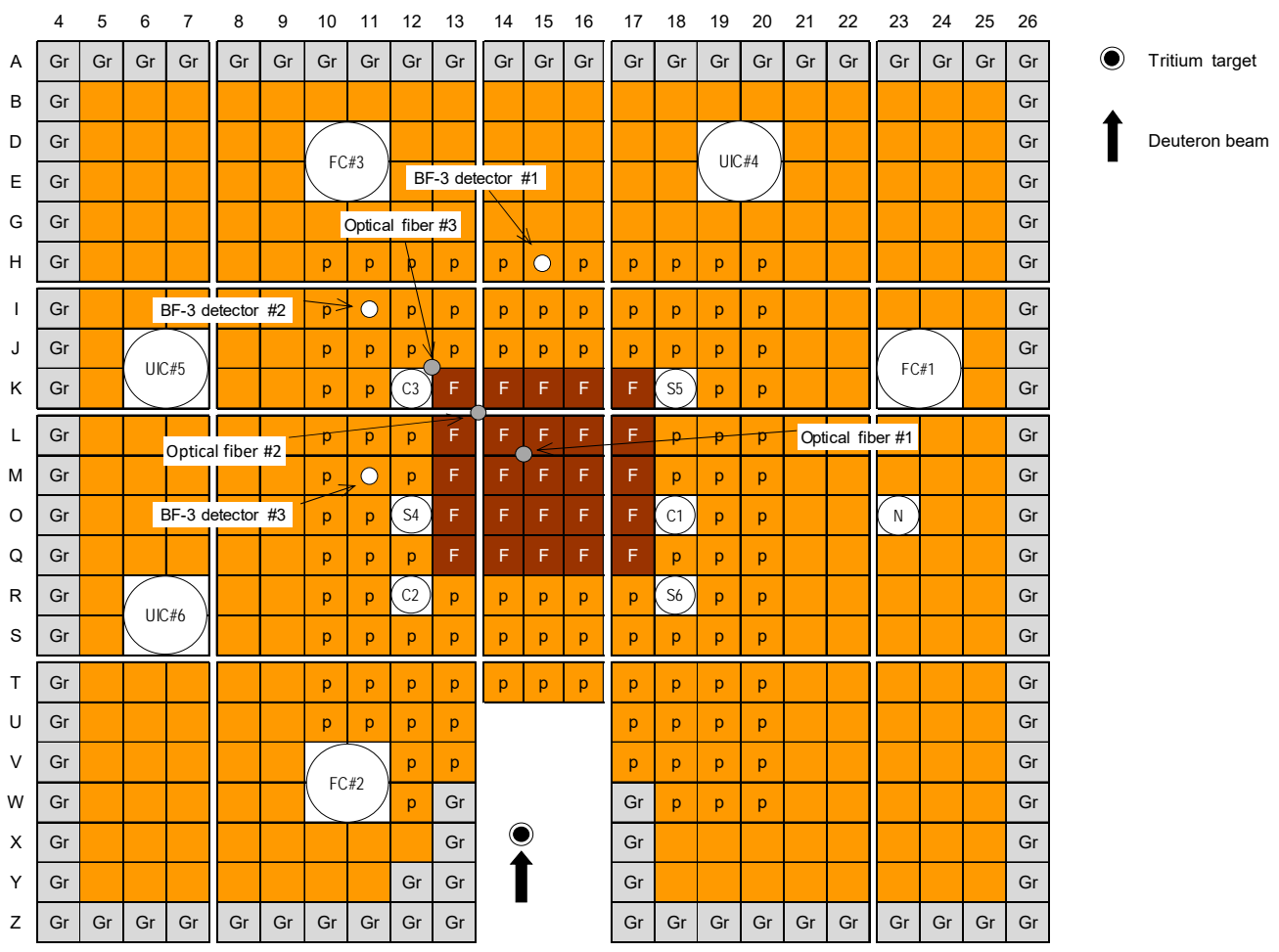

Fig. 6 Top view of ADS core with $14 \mathrm{MeV}$ neutrons

(\# of HEU plates: 3000; subcritical core) 


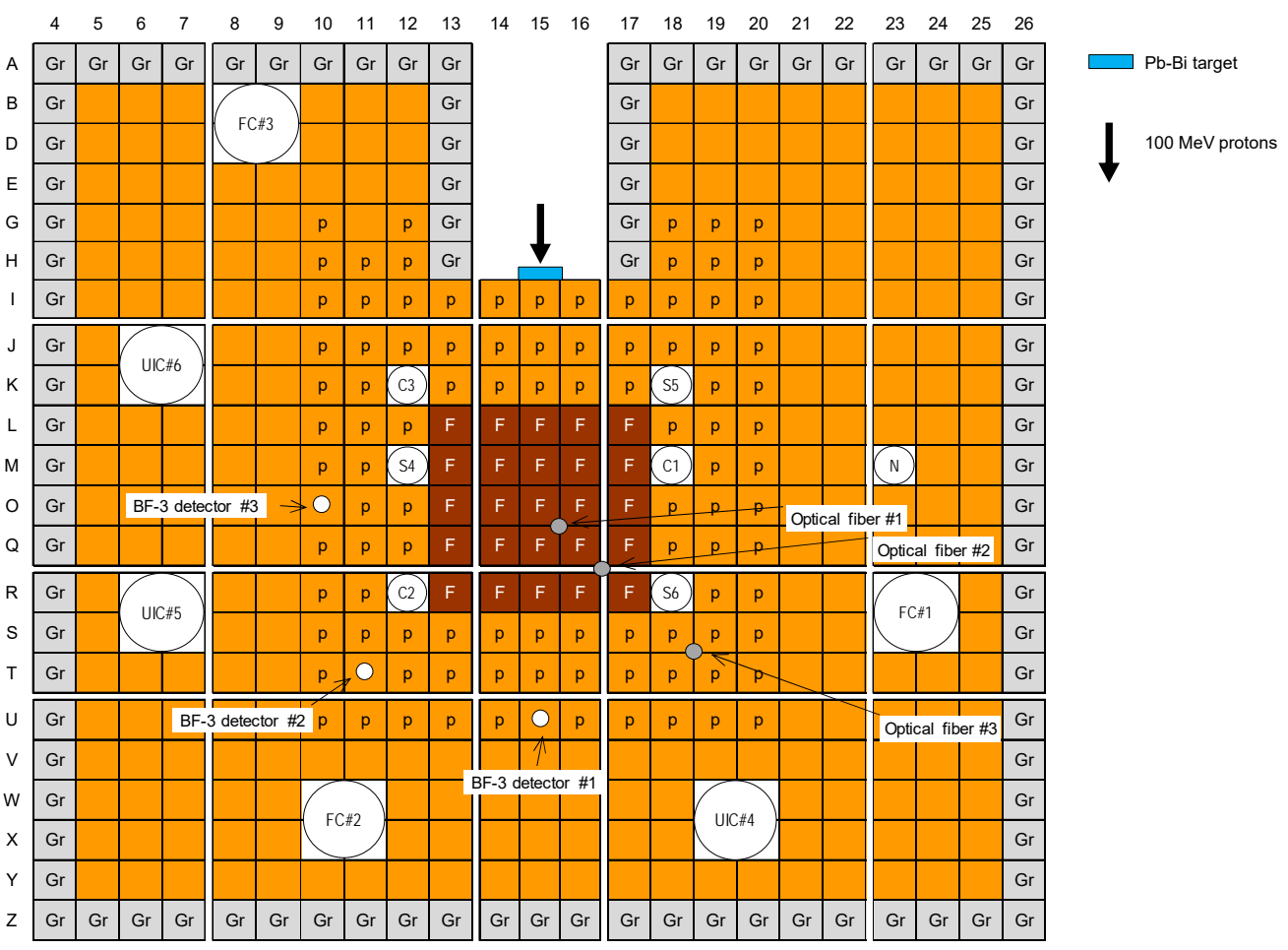

Fig. 7 Top view of ADS core with $100 \mathrm{MeV}$ protons (Pb-Bi target)

(\# of HEU plates: 3000; subcritical core) 


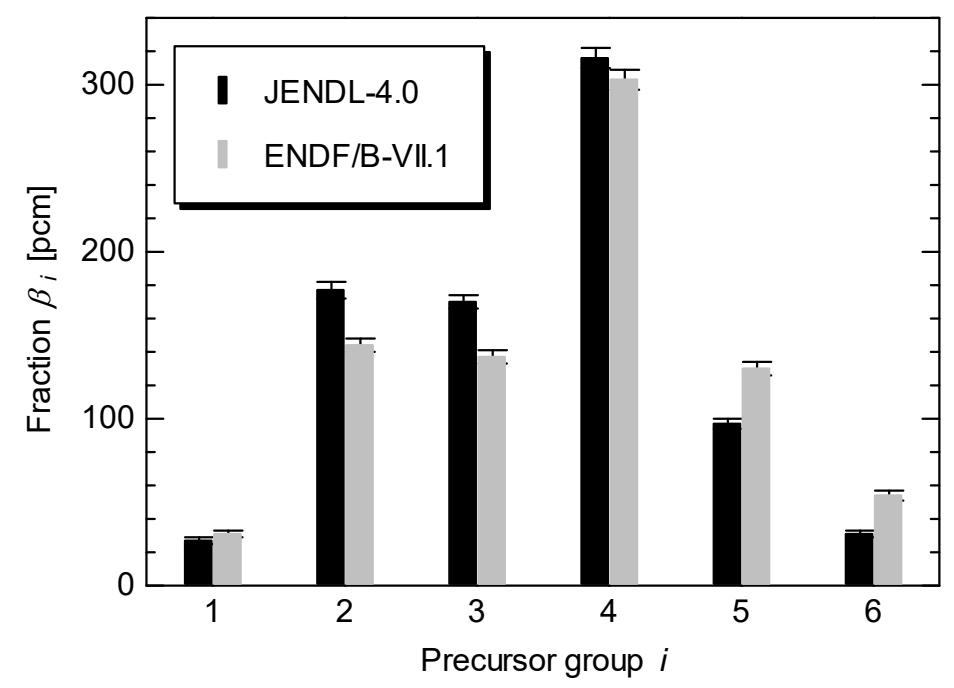

Fig. 8 Comparison between fraction $\beta_{i}(i=1$ to 6$)$ by JENDL-4.0 and ENDF/B-VII.1 (\# of HEU plates: 3016; critical state in Fig. 1 and Table II)

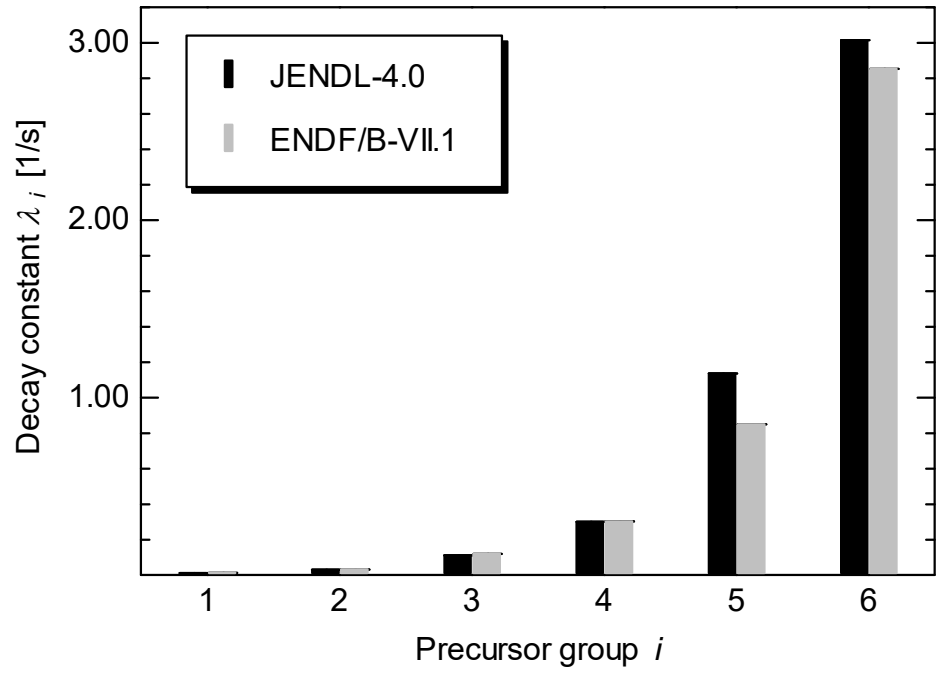

Fig. 9 Comparison between decay constant $\lambda_{i}(i=1$ to 6$)$ by JENDL-4.0 and ENDF/B-VII.1 (\# of HEU plates: 3016; critical state in Fig. 1 and Table II) 
Table I Dimensions of components in fuel assemblies

\begin{tabular}{cc}
\hline Component & Thickness and length $[\mathrm{mm}]$ \\
\hline $1 / 16$ "HEU & 1.5875 \\
$1 / 8$ "p & 3.158 \\
$10 " \mathrm{p}$ & 254.00 \\
$1 / 4$ "PE & 6.300 \\
$1 / 2$ "PE & 12.500 \\
2 "Gr & 50.80 \\
$1 / 16 " \mathrm{Al}$ & 1.5875 \\
\hline
\end{tabular}


Table II Positions of control and safety rods at critical state [mm] (\# of HEU plates: 3016; critical core in Fig. 1)

\begin{tabular}{cccccc}
\hline \multicolumn{3}{c}{ Control rod } & \multicolumn{3}{c}{ Safety rod } \\
$\mathrm{C} 1$ & $\mathrm{C} 2$ & $\mathrm{C} 3$ & $\mathrm{~S} 4$ & $\mathrm{~S} 5$ & $\mathrm{~S} 6$ \\
\hline 1200.00 & 1200.00 & 630.01 & 1200.00 & 1200.00 & 1200.00 \\
\hline \multicolumn{5}{c}{$(1200[\mathrm{~mm}]:$ Position of upper limit $)$}
\end{tabular}

Table III Positions of control and safety rods at critical state [mm] (\# of HEU plates: 3008; critical core in Fig. 2)

\begin{tabular}{cccccc}
\hline & Control rod & & \multicolumn{3}{c}{ Safety rod } \\
$\mathrm{C} 1$ & $\mathrm{C} 2$ & $\mathrm{C} 3$ & $\mathrm{~S} 4$ & $\mathrm{~S} 5$ & $\mathrm{~S} 6$ \\
\hline 1200.00 & 723.31 & 1200.00 & 1200.00 & 1200.00 & 1200.00 \\
\hline
\end{tabular}

(1200 [mm]: Position of upper limit) 
Table IV Comparison between measured and calculated reactivity [pcm] with JENDL-4.0 (\# of HEU plates: 3016; critical core in Fig. 1 and Table II)

\begin{tabular}{cccc}
\hline & $\rho_{\mathrm{J} 40}^{\text {cal }}$ & $\rho_{\mathrm{J} 40}^{\text {exp }}$ & $\mathrm{C} / \mathrm{E}\left(\rho_{\mathrm{J} 40}^{\mathrm{cal}} / \rho_{\mathrm{J} 40}^{\text {exp }}\right)$ \\
\hline Excess reactivity & $259.9 \pm 5.7$ & $271.7 \pm 0.1$ & $0.96 \pm 0.02$ \\
C1 rod worth & $876.1 \pm 5.7$ & $867.4 \pm 3.9$ & $1.01 \pm 0.01$ \\
C2 rod worth & $154.8 \pm 5.7$ & $142.8 \pm 3.5$ & $1.08 \pm 0.05$ \\
C3 rod worth & $529.2 \pm 5.7$ & $506.4 \pm 4.1$ & $1.05 \pm 0.01$ \\
\hline
\end{tabular}

MCNP6.1 with JENDL-4.0: $\beta_{\text {eff }}=813 \pm 10[\mathrm{pcm}], \Lambda=31.67 \pm 0.07[\mu \mathrm{s}]$

Table V Comparison between measured and calculated reactivity [pcm] with ENDF/B-VII.1 (\# of HEU plates: 3016; critical core in Fig. 1 and Table II)

\begin{tabular}{cccc}
\hline & $\rho_{\mathrm{E} 71}^{\mathrm{cal}}$ & $\rho_{\mathrm{E} 71}^{\exp }$ & $\mathrm{C} / \mathrm{E}\left(\rho_{\mathrm{E} 71}^{\mathrm{cal}} / \rho_{\mathrm{E} 71}^{\exp }\right)$ \\
\hline Excess reactivity & $253.9 \pm 5.6$ & $229.8 \pm 0.3$ & $1.10 \pm 0.02$ \\
C1 rod worth & $862.5 \pm 5.7$ & $718.8 \pm 3.2$ & $1.20 \pm 0.01$ \\
C2 rod worth & $138.2 \pm 5.6$ & $118.3 \pm 2.9$ & $1.17 \pm 0.05$ \\
C3 rod worth & $513.1 \pm 5.7$ & $419.6 \pm 4.5$ & $1.22 \pm 0.01$ \\
\hline
\end{tabular}

MCNP6.1 with ENDF/B-VII.1: $\beta_{\text {eff }}=801 \pm 10$ [pcm], $\Lambda=31.26 \pm 0.07[\mu \mathrm{s}]$ 
Table VI Comparison between measured and calculated reactivity [pcm] with JENDL-4.0 (\# of HEU plates: 3008; critical core in Fig. 2 and Table III)

\begin{tabular}{cccc}
\hline & $\rho_{\mathrm{J} 40}^{\mathrm{cal}}$ & $\rho_{\mathrm{J} 40}^{\mathrm{exp}}$ & $\mathrm{C} / \mathrm{E}\left(\rho_{\mathrm{J} 40}^{\mathrm{cal}} / \rho_{\mathrm{J} 40}^{\exp }\right)$ \\
\hline Excess reactivity & $106.1 \pm 5.7$ & $100.2 \pm 1.7$ & $1.06 \pm 0.06$ \\
\hline MCNP6.1 with JENDL-4.0: $\beta_{\text {eff }}=812 \pm 10[\mathrm{pcm}], \Lambda=31.57 \pm 0.07[\mu \mathrm{s}]$
\end{tabular}

Table VII Comparison between measured and calculated reactivity [pcm] with ENDF/B-VII.1 (\# of HEU plates: 3008; critical core in Fig. 2 and Table III)

\begin{tabular}{cccc}
\hline & $\rho_{\mathrm{E} 71}^{\mathrm{cal}}$ & $\rho_{\mathrm{E} 71}^{\exp }$ & $\mathrm{C} / \mathrm{E}\left(\rho_{\mathrm{E} 71}^{\mathrm{cal}} / \rho_{\mathrm{E} 71}^{\exp }\right)$ \\
\hline Excess reactivity & $97.6 \pm 5.6$ & $84.7 \pm 1.5$ & $1.15 \pm 0.07$ \\
\hline
\end{tabular}

MCNP6.1 with ENDF/B-VII.1: $\beta_{\text {eff }}=802 \pm 10$ [pcm], $\Lambda=31.30 \pm 0.07[\mu \mathrm{s}]$ 
Table VIII Comparison between kinetic parameters by MCNP6.1 with JENDL-4.0 and ENDF/B-VII.1 (\# of HEU plates: 3016 in Fig. 1)

\begin{tabular}{lccc}
\hline & Parameter & JENDL-4.0 & ENDF/B-VII.1 \\
\hline Super-critical core & $\beta_{\text {eff }[\mathrm{pcm}]}$ & $813 \pm 10$ & $801 \pm 10$ \\
(clean core) & $\Lambda[\mu \mathrm{s}]$ & $31.67 \pm 0.07$ & $31.26 \pm 0.07$ \\
& Rossi- $\alpha\left[\mathrm{s}^{-1}\right]$ & $256.89 \pm 3.11$ & $256.18 \pm 3.11$ \\
Critical core & $\beta_{\text {eff }}[\mathrm{pcm}]$ & $818 \pm 10$ & $800 \pm 10$ \\
(partial insertion of C3 rod) & $\Lambda[\mu \mathrm{s}]$ & $30.91 \pm 0.07$ & $30.69 \pm 0.07$ \\
& Rossi- $\alpha\left[\mathrm{s}^{-1}\right]$ & $264.55 \pm 3.23$ & $260.66 \pm 3.17$ \\
\hline
\end{tabular}

Table IX Comparison between kinetic parameters by MCNP6.1 with JENDL-4.0 and ENDF/B-VII.1 (\# of HEU plates: 3008 in Fig. 2)

\begin{tabular}{lccc}
\hline & Parameter & JENDL-4.0 & ENDF/B-VII.1 \\
\hline Super-critical core & $\beta_{\text {eff }[\mathrm{pcm}]}$ & $812 \pm 10$ & $802 \pm 10$ \\
(clean core) & $\Lambda[\mu \mathrm{s}]$ & $31.57 \pm 0.07$ & $31.30 \pm 0.07$ \\
& Rossi- $\alpha\left[\mathrm{s}^{-1}\right]$ & $257.22 \pm 3.11$ & $256.35 \pm 3.11$ \\
Critical core & $\beta_{\text {eff }[\mathrm{pcm}]}$ & $821 \pm 10$ & $801 \pm 10$ \\
(partial insertion of C2 rod) & $\Lambda[\mu \mathrm{s}]$ & $31.33 \pm 0.07$ & $30.03 \pm 0.07$ \\
& Rossi- $\alpha\left[\mathrm{s}^{-1}\right]$ & $262.22 \pm 3.17$ & $258.09 \pm 3.15$ \\
\hline
\end{tabular}


Table X Comparison between kinetic parameters by MCNP6.1 with JENDL-4.0 and ENDF/B-VII.1 (\# of HEU plates: 3000; subcritical core in Figs. 6 and 7)

\begin{tabular}{lccc}
\hline & Parameter & JENDL-4.0 & ENDF/B-VII.1 \\
\hline Subcritical core & $\beta_{\text {eff }[\mathrm{pcm}]}$ & $806 \pm 10$ & $796 \pm 10$ \\
(clean core) & $\Lambda[\mu \mathrm{s}]$ & $31.71 \pm 0.07$ & $31.42 \pm 0.07$ \\
& Rossi- $\alpha\left[\mathrm{s}^{-1}\right]$ & $254.05 \pm 3.07$ & $253.35 \pm 3.09$ \\
\hline
\end{tabular}


Table XI Measured prompt neutron decay constants $\alpha\left[\mathrm{s}^{-1}\right]$ deduced by least-square fitting method, subcriticality $\rho \$[\$]$ (dollar units) by extended area ratio method, and $\beta_{\text {eff }} / \Lambda$ $\left[\mathrm{s}^{-1}\right]$ by $\alpha$-fitting method (\# of HEU plates: 3000; subcritical core with $14 \mathrm{MeV}$ neutrons in Fig. 6)

\begin{tabular}{ccccc}
\hline Detector & $\alpha\left[\mathrm{s}^{-1}\right]$ & $\rho \$[\$]$ & $\left(\beta_{\text {eff }} / \Lambda\right)^{\text {exp }}\left[\mathrm{s}^{-1}\right]$ & $\mathrm{C} / \mathrm{E}$ \\
\hline BF-3\#1 & $294.78 \pm 29.27$ & $0.0228 \pm 0.0070$ & $288.20 \pm 93.30$ & $0.88 \pm 0.29$ \\
BF-3 \#2 & $226.96 \pm 23.31$ & $0.0158 \pm 0.0054$ & $223.44 \pm 79.47$ & $1.14 \pm 0.41$ \\
BF-3 \#3 & $258.58 \pm 12.34$ & $0.0194 \pm 0.0027$ & $253.66 \pm 37.32$ & $1.00 \pm 0.15$ \\
Fiber \#1 & $248.38 \pm 39.04$ & $0.0207 \pm 0.0056$ & $243.36 \pm 72.07$ & $1.04 \pm 0.31$ \\
Fiber \#2 & $229.95 \pm 14.51$ & $0.0200 \pm 0.0032$ & $225.45 \pm 38.73$ & $1.13 \pm 0.19$ \\
Fiber \#3 & $273.99 \pm 26.24$ & $0.0261 \pm 0.0056$ & $267.02 \pm 62.56$ & $0.95 \pm 0.22$ \\
\hline
\end{tabular}

MCNP6.1 with JENDL-4.0: $\beta_{\text {eff }}=806 \pm 10[\mathrm{pcm}], \Lambda=31.71 \pm 0.07[\mu \mathrm{s}]$ $\left(\beta_{\text {eff }} / \Lambda\right)_{\mathrm{J} 40}^{\mathrm{cal}}\left(\right.$ Rossi- $\alpha$ value in MCNP6.1) $=254.05 \pm 3.07\left[\mathrm{~s}^{-1}\right] ; \mathrm{C} / \mathrm{E}=\left(\beta_{\text {eff }} / \Lambda\right)_{\mathrm{J} 40}^{\mathrm{cal}} /\left(\beta_{\text {eff }} / \Lambda\right)^{\text {exp }}$ 
Table XII Measured prompt neutron decay constants $\alpha\left[\mathrm{s}^{-1}\right]$ deduced by least-square fitting method, subcriticality $\rho \$[\$]$ (dollar units) by extended area ratio method, and $\beta_{\text {eff }} / \Lambda$ $\left[\mathrm{s}^{-1}\right]$ by $\alpha$-fitting method (\# of HEU plates: 3000; subcritical core with spallation neutrons in Fig. 7)

\begin{tabular}{ccccc}
\hline Detector & $\alpha\left[\mathrm{s}^{-1}\right]$ & $\rho \$[\$]$ & $\left(\beta_{\text {eff }} / \Lambda\right)^{\mathrm{exp}}\left[\mathrm{s}^{-1}\right]$ & $\mathrm{C} / \mathrm{E}$ \\
\hline BF-3 \#1 & $276.25 \pm 7.17$ & $0.0900 \pm 0.0011$ & $253.43 \pm 7.25$ & $1.00 \pm 0.03$ \\
BF-3 \#2 & $300.62 \pm 7.03$ & $0.0966 \pm 0.0011$ & $274.13 \pm 7.15$ & $0.93 \pm 0.03$ \\
BF-3 \#3 & $259.96 \pm 6.00$ & $0.0899 \pm 0.0011$ & $238.53 \pm 6.18$ & $1.07 \pm 0.03$ \\
Fiber \#1 & $283.79 \pm 15.38$ & $0.0973 \pm 0.0025$ & $258.62 \pm 15.49$ & $0.98 \pm 0.06$ \\
Fiber \#2 & $360.05 \pm 64.85$ & $0.1139 \pm 0.0087$ & $323.24 \pm 63.19$ & $0.79 \pm 0.15$ \\
Fiber \#3 & $269.83 \pm 26.36$ & $0.1392 \pm 0.0039$ & $236.85 \pm 24.04$ & $1.07 \pm 0.11$ \\
\hline
\end{tabular}

MCNP6.1 with JENDL-4.0: $\beta_{\text {eff }}=806 \pm 10[\mathrm{pcm}], \Lambda=31.71 \pm 0.07[\mu \mathrm{s}]$, $\left(\beta_{\text {eff }} / \Lambda\right)_{\mathrm{J} 40}^{\mathrm{cal}}\left(\right.$ Rossi- $\alpha$ value in MCNP6.1) $=254.05 \pm 3.07\left[\mathrm{~s}^{-1}\right] ; \mathrm{C} / \mathrm{E}=\left(\beta_{\text {eff }} / \Lambda\right)_{\mathrm{J} 40}^{\mathrm{cal}} /\left(\beta_{\text {eff }} / \Lambda\right)^{\text {exp }}$ 